\title{
OPEN
}

\section{1 \\ The Future of the Academic Book: The Role of Booksellers}

\section{Peter Lake}

\begin{abstract}
Universities, lecturers, and students are faced with a plethora of choice when it comes to courseware, choices that both complement and replace the traditional textbook. The future role of university booksellers will be to provide the best discovery, delivery, and evaluation tools to help lecturers and students choose and get the most benefit from their learning resources. Whilst booksellers will continue to offer a retail presence for students, their business model will evolve and become more reliant on services and software revenues from universities.
\end{abstract}

Keywords: booksellers; courseware; delivery; discovery; evaluation; learning resources; services; software; textbook

Lyons, Rebecca E. and Samantha J. Rayner (eds). The Academic Book of the Future. Basingstoke: Palgrave Macmillan, 2016. DOI: 10.1057/9781137595775.0019. 
At a time when the global demand for tertiary education is at its highest and set for sustained growth in the years to come, textbooks, so long a staple of undergraduate courses, are in decline. Student numbers are going up, sales of textbooks in all formats are going down and their traditional role as the supporting guide or narrative to a subject is being challenged. Growth in demand for tertiary education and the impact of the Internet and the networked society on how that education is delivered mean that students and educators now have a much wider and richer array of learning resources (referred to here as 'courseware' for convenience) to support course delivery, study and student success. This chapter focusses on the undergraduate textbook as this has long been the main product offered by university booksellers. What is the future role for those booksellers as universities and students adopt new ways of course delivery and new courseware?

That textbooks are in decline is not a surprise. The networked society has not been kind to the traditional content providers. The music, film, newspaper, and publishing industries have all been disrupted as consumers become producers and make their music available via file-sharing services and their videos on YouTube whilst disseminating knowledge on Wikipedia and obtaining and spreading news on social media. Many established players have faltered, new digital competition has emerged, and publishers are rethinking their business models and value propositions.

Perhaps the surprise is how well textbooks continue to perform compared to other areas of publishing such as business, professional, and financial, where online and data-driven solutions have all but replaced the book. In part this is due to the fact that textbooks do their job well - providing a well-structured and user-friendly guide to a topic and, in part, due to the naturally cautious approach of faculty to making changes to the way established modules and courses are delivered.

But this is changing as some major trends impact on how universities deliver their courses. First, the increase in demand for tertiary education is challenging the traditional university model. Globally, the tertiary education participation rate for 25-34-year-olds has increased to just shy of 40 per cent compared with 25 per cent for 55-64-year-olds with most of this growth coming from Asia and emerging markets. The traditional university model, despite new universities being established, cannot meet this demand, and there is a strong growth in distance learning, with new digital platforms being deployed to meet this demand. 
Allied to this has been the growth in massive open online courses (MOOCs), some carrying college credits. Over 6 million students are enrolled on MOOCS, some of which are taught by among the most distinguished of professors. MOOCs have not only been part of the response to the increasing demand for tertiary education but have also been a clear demonstration of the potential for lecture capture, live streaming and video-on-demand as a core component of course delivery. A second trend is the flipped classroom and blended learning where instructional content is delivered outside the lecture hall, with lectures becoming smaller, discussion-based groups. Students do their research outside of lectures by watching online lectures, collaborating in online discussions and, of course, accessing and reading recommended books. Textbooks from commercial publishers still play a part, but they are now joined by open textbooks, MOOCs, online lectures and other resources, including lecturer-authored material. Add to this mix student vloggers, the impact of gaming on how content is presented and experienced and the rise of automated paper production based on text mining, and it is clear that courseware now comes in multiple formats, from multiple suppliers with competing business models.

Another reason the textbook may be less relevant in the future: publishers are racing to replace them with new digital services. These new services blend traditional textbook content with adaptive learning technologies, embedded testing and assessment features, integrated assignment functionality, personal study wallets and records, and collaborative learning tools. These services are being widely adopted in the US and there are some very encouraging indications that these more personalised learning pathways are producing better results for students and educators.

So if the university bookseller is going to be selling fewer textbooks, what will its role be in the future? Traditionally, the bookseller has been on campus providing a retail service to students and working with faculty on the selection and sourcing of the most appropriate learning resources. That business model will have to change and evolve. The student retail model will certainly persist and change as a broader range of goods and services will be offered to students. The move to digital and new forms of courseware will, however, make on-campus retailing uneconomic at some universities. Overall, the emphasis for booksellers will shift to providing services, software and solutions to universities. It already has in a number of markets. 
There will be three main components of this shift: investment in and development of learning resources management services; digital content delivery platforms; and data analytic services. Behind the development of all three is the knowledge that with the wide range of courseware now available to universities only a very small percentage of their requirements are ever going to be met by a single supplier or single service. Lecturers and universities will be taking resources from multiple sources and booksellers are well placed to work with universities on the selection of resources, their deployment and integration, and in providing evaluation tools.

Learning resource management will be a key enabler for universities going forward as they blend resources from multiple providers and in multiple formats with their own self-generated resources. Booksellers are already helping with the discovery and selection of resources, with services such as Barnes \& Noble College's Faculty Enlight, Amazon's CourseMaterials Tool, and Follett's Faculty Discover. Although these services have a focus on textbooks, they are already broadening their coverage to include MOOCs, open educational resources, YouTube videos, and have facilities for lecturers to upload and include their own material. Soon, all courseware will be covered and as part of the discovery process lecturers will be able to see what is being used at other institutions and to share their recommendations and experiences. As well as discovery and selection, these services will offer value for money assessment and purchasing options to help with budgeting and planning. And, of course, these services will not only be valuable to lecturers but will also be used by students. There will quickly develop a comprehensive database of student opinion and feedback that will inform both courseware selection and the future value proposition development of publishers and others.

Digital content platforms are another area of development for booksellers, with services such as Yuzu, Blackwells Learning and Kortext. Today these are ebook platforms that offer the benefit of aggregation and integration. Universities want ebooks tightly integrated with their virtual learning environments (VLEs) so it makes sense to specify only one platform for any given institution to deliver content from multiple suppliers. The focus for most of these ebook platforms, therefore, is not on selling directly to students but rather working with universities to provide students with a common ebook experience and to work with lecturers in integrating specific pieces of content into their VLE module 
design. This also fits in with the trend in some markets for courseware to be provided to students by their university as part of their course fee.

A second, important market for these platforms is and will be governments in a number of emerging markets where ebooks offer a more reliable route of getting textbooks to students, especially the high percentage of distance learners in these markets. As these platforms develop, they will offer the benefit of disaggregation as content provision will move to open-market models, and content owners will allow much more customer-defined purchasing of packages of content to be used within lecturer-curated courseware. With this in mind, the capabilities of these platforms are being expanded to include integration with adaptive learning software and will offer lecturers both authoring tools and course-building functionality. Finally, these platforms will offer all the multiple types of courseware available to lecturers and students locally and will provide seamless integration into any and all of the publishers' new services that are centrally hosted.

The third area of development is in analytics and evaluation services. The economic benefits of tertiary education remain very compelling: across the Organisation for Economic Co-operation and Development (OECD) the lifetime earning capacity for someone with a tertiary education is 50 per cent greater than someone with a higher secondary one. ${ }^{1}$ The cost of providing that education is also increasing, either as a cost to the general taxpayer, or in the fees charged to or debts accumulated by students. Governments, universities, and students all have a significant interest in the most effective learning pathways and in developing employability skills alongside academic skills. Reducing the time and cost to gain a degree and/or increasing the social and economic benefit of a degree are key policy areas.

Booksellers are already working with universities on providing data and analysis that, for example, compares the impact of lecture attendance, library usage, and textbook usage to degree outcomes (attendance and textbook usage are highly correlated to degree outcomes, library usage less so). They are working with lecturers on analysing different patterns of ebook usage within student cohorts and feeding data into student engagement systems. This is really just the tip of an iceberg as more and more data will be available to universities on how, where, and when students study.

Data models will be developed to include all courseware usage, VLE usage, library and library platform usage, attendance, and work 
completion data alongside levels of interaction with fellow students and lecturers. In some instances, booksellers will help develop these models and services - especially those who work with a number of universities within a market - whilst in many others they will be able to provide university specific and comparative data on the effectiveness of the different courseware available to institutions. Booksellers will work with universities and lecturers on determining what is the best combination of content, tools, and platforms for producing the best outcomes for their students.

So from one perspective the primary role of booksellers will not change: in the future booksellers will still provide a retail service to students and will still work with faculty on the selection and sourcing of the most appropriate learning resources. But the bookselling business model will change. The retail offer will remain, and will have to broaden to remain economically viable. However, the investment and development focus, particularly for the larger booksellers will shift and will be on developing richer resources, platforms, and data to help universities provide the best courseware and learning outcomes for their students. In doing this, booksellers will focus more on their core asset: a deep understanding of and relationship with universities, lecturers, and students. As a result, they will find new, exciting ways to support university and student success.

\section{Note}

1 See OECD (2014) Education at a Glance 2014: OECD Indicators, http://www.oecd. org/edu/Education-at-a-Glance-2014.pdf, accessed 9 September 2015.

(c) (i) Except where otherwise noted, this work is licensed under a a copy of this license, visit https://creativecommons.org/version4 